\title{
Financing sources and policies for renewable energies
}

\author{
A. Ivanova, A. Gamez \& M. Ángeles \\ Autonomous University of Southern Baja California, Mexico
}

\begin{abstract}
Renewable energy (RE) has a significant potential to mitigate global climate change, address regional and local environmental concerns, reduce poverty and increase energy security. The challenge is to provide the right policy frameworks and financial tools that will enable RE to achieve its market potential and move from the margins of energy supply into the mainstream.

Policy-makers thus have a mandate to take action and, since most of the capital for this greening will not come from public treasuries, most of this action will need to focus on creating enabling frameworks and finance mechanisms for technology R\&D, commercialization and investment.

Renewable energies, although subject to the same market forces as conventional energy sources, involve markedly different technologies and thus their financing requires new thinking, new risk management approaches and new forms of capital.

After examining and analyzing the financing trends for renewable energies, we conclude that market signals alone - even when incorporating carbon pricing - have not been sufficient to trigger significant renewable energies growth. Therefore the importance of the well-designed policies is crucial. To be as effective as possible, these must be taking into account the state of the technology, available RE resources, and responding to local political, economic, social and cultural needs and conditions.
\end{abstract}

Keywords: renewable energies, policies, financing, mitigation.

\section{Introduction}

Government policies are required for a substantial increase in deployment of renewable energy. Market signals alone - even when incorporating carbon 
pricing - have not been sufficient to trigger significant RE growth. Multiple success stories from around the world demonstrate that policies can have a substantial impact on RE development and deployment. Significant improvements in energy efficiency and a global transition to renewable energy will require huge investments in national and local energy infrastructures in every country over the coming decade. These investments will need to come from both the public and private sectors, and they will have to take many forms: including financial incentives from government; loans and capital investment from banks, private investors, venture capital funds and communities; as well as new innovative markets that contribute to the benefits of renewable energy and energy efficiency.

\section{Trends in RE policies}

Growth in RE capacity and energy production have increased rapidly over the past several years, with several technologies experiencing average annual growth rates in the double digits. Although renewable 19 technologies still account for a relatively small share of total global energy use, in 2008 alone the 20 world added an estimated 65 gigawatts (GW) of new renewable electric capacity, accounting for 41 percent of total capacity additions that year. Several factors are driving this rapid growth in RE markets [14], but government policies have played a crucial role in accelerating the deployment of RE technologies.

Until the early 1990s, few countries had enacted policies to promote RE. Since then, and particularly since the early- to mid-2000s, policies have begun to emerge in an increasing number of countries at the national, provincial/state, and municipal levels. Initially, most policies adopted were in developed countries, but more recently a growing number of developing countries have enacted policy frameworks to promote RE.

In 2005, an estimated 45 countries - including 10 developing countries - had policy targets for RE [12]; by early 2009, the number of countries with policy targets had increased to at least 73 [14].

Renewable Portfolio Standards (RPS) or quotas are also widely used and, by early 2009, had been enacted by an estimated 9 countries at the national level and by at least 40 states or provinces [15]. RE's share of new global electricity generation has risen in line with the increase in FIT and RPS policies.

In addition, an increasing number of governments are adopting incentives and mandates to advance renewable transport fuels and renewable heating technologies. For example, in the 12 countries analyzed for the IEA, the number of policies introduced to support renewable heating either directly or indirectly increased from five in 1990 to more than 55 by May 2007 [9].

\section{Financing trends}

In response to the increasingly supportive policy environment, the RE sector has seen rapidly increasing levels of financing in the past few years, with $\$ 116$ 
billion of new financial investment in 2008, up from 15.5 billion USD in 2002 [8].

Financing has been increasing into the five areas of i) $R \& D$ (which is covered in the previous subsection); ii) technology development and commercialization; iii) equipment manufacturing and sales; iv) project construction; and v) the refinancing and sale of companies. The trends in financing going into these areas represent successive steps in the innovation process and provide indicators of the RE sector's current and expected growth, as follows:

$\checkmark \quad$ Trends in R\&D funding and technology investment (i, ii) are indicators of the mid- to long-term expectations for the sector - investments are being made that will only begin to pay off several years down the road.

$\checkmark$ Trends in manufacturing investment (iii) are an indicator of near term expectations for the sector - essentially, that the growth in market demand will continue.

$\checkmark$ Trends in new generating capacity investment (iv) are an indicator of current sector activity.

$\checkmark$ Trends in industry mergers and acquisitions (v) are an indicator of the overall maturity of the sector, since increasing refinancing activity over time indicates that larger more conventional investors are entering the sector, buying up successful early investments from first movers.

\section{Key drivers, opportunities and benefits}

The financing trends are being driven in great part by government policies, and policies for the deployment of RE are, in turn, driven by several environmental, economic, social and security goals. The drivers can be differentiated - as factors that are pushing for the deployment of RE policy (for example climate change and the need to reduce fossil fuel emissions from the energy sector), from opportunities (which, for example, lead a country to invest in RE with the explicit goal of developing a new domestic or export industry, irrespective of the drivers), and from the benefits of promoting RE, which are generally the flip side of the drivers or opportunities (for example, reduced emissions, improved health, more jobs, better skills and so on). The distinctions among these factors are necessarily close and overlapping.

The relative importance of the drivers, opportunities or benefits varies from country to country and may vary over time, as changing circumstances affect economies, attitudes and public perceptions.RE technologies offer governments the potential to realize multiple policy goals, sometimes simultaneously, that cannot be obtained to the same extent or quality through the development and use of conventional energies.

Key drivers for policies to advance RE are:

$\checkmark$ Mitigating climate change

$\checkmark \quad$ Enhancing access to energy

$\checkmark$ Improving security of energy supply and use

$\checkmark$ Decreasing environmental impacts of energy supply

$\checkmark$ Decreasing health impacts associated with energy production and use. 
And, a key issue which is both a driver and an opportunity: fostering economic development and job creation.

\subsection{Climate change mitigation}

$\mathrm{RE}$ is a major tool for climate change mitigation, its potential being the focus of this report. The degree to which RE mitigates climate change depends on many factors, addressed in the various sections of this chapter and report.

As a result, RE is an integral aspect of government strategies for reducing carbon dioxide (and other) emissions in many countries, including all member states of the European Union. Several U.S. states, including California and Washington, and numerous U.S. cities, from Chicago to Miami, have adopted RE targets and policies to advance their strategies for addressing climate change [18].

Developing countries are also enacting RE policies in order to address climate change, among other goals. In June 2008, in launching India's National Action Plan on Climate Change, Prime Minister Dr. Manmohan Singh said that: "Our vision is to make India's economic development energy-efficient. Over a period of time, we must pioneer a graduated shift from economic activity based on fossil fuels to one based on non-fossil fuels and from reliance on non renewable and depleting sources of energy to renewable sources of energy". The 2009 meeting of Leaders of Pacific Island Countries observed that in addition to RE offering the promise of cost-effective, reliable energy services to rural households it will also provide a contribution to global greenhouse gas mitigation efforts [15].

\subsection{Access to energy}

Renewable energies have the ability to effectively and quickly provide access to modern energy services, including lighting and refrigeration, and therefore RE plays an important role in achieving the millennium development goals [17]. Distributed RE can avoid the need for costly transport and distribution networks, which can make energy more costly for people in poor, remote communities than it is for urban populations.

Access to modern, cleaner energy also reduces indoor air pollution, improving infant and maternal health; it advances education, agriculture and communications; it improves income generation; and it supports hunger eradication.

Because of their modularity and flexible size, RE technologies have received increased attention from governments looking to electrify rural and remote areas. Another significant benefit of RE is that it often provides the lowest-cost option for remote and off-grid areas. Programs to increase the rate of access to energy and based on RE have occurred in many countries. For example, in 1996, the Government of Nepal established the Alternative Energy Promotion Centre for RE technologies in non-electrified areas to improve the well-being of the country's impoverished rural population [10]. Likewise in Nigeria, where twothirds of the population lives in rural areas, the government's Renewable Energy 
Master Plan calls for RE deployment to improve energy services to the poor and thereby advance rural economic development [13]. Other developing countries including China, Bolivia, Bangladesh, India, Mexico, Nepal, Pakistan, South Africa, and Zambia - have adopted RE policies for providing energy access to rural areas.

\subsection{Energy security}

Energy security issues encompass:

$\checkmark$ the technical underpinnings of the energy infrastructure so that it seamlessly transports and delivers energy without failure or threat of failure;

$\checkmark$ concerns that incentives within markets and economic regulation will not encourage;

$\checkmark$ sufficient investment in the energy system to ensure enough infrastructure (whether generation facilities, ports, storage and so on) to meet energy demand;

$\checkmark$ concerns that a physical resource (i.e. oil or natural gas) will not be delivered as contracted, thereby limiting energy use and raising prices;

$\checkmark$ concerns that the price of a physical resource, such as oil or gas, may rise to such an extent that it becomes unaffordable to increasing numbers of people, thus causing social unrest or difficulty;

$\checkmark$ concerns that supply chains will not be able to deliver the technologies, parts and skills to enable deployment or operation of technologies, including RE;

$\checkmark$ and concerns that the international relationships and foreign policies between countries may exacerbate concerns of resource access, including energy.

The addition of RE technologies to the broad energy mix alters these concerns in different ways. However, RE power plants may make a power grid more robust against grid failures and break-downs, thereby increasing the energy security of that system. Decentralizing energy systems, via RE or other options, can also reduce vulnerability to energy disruptions that might result from damage to infrastructure resulting from natural disaster or attack.

RE can diversify energy supply portfolios. Diversity has a number of energy system benefits but the use of RE may also displace the need for other fuels. This is particularly valuable for countries that import large amounts of energy, or are particularly dependent on one fuel source or supplier. For example, China established its 2005 Renewable Energy Law, among others, to diversify energy supplies and safeguard energy security [13]. Brazil has promoted ethanol from sugarcane as an alternative to fossil transport fuels for thirty years to decrease dependency on imported fuels.

\subsection{Fostering economic development and job creation}

The European Union underlines the potential of job creation - especially in rural and isolated areas - in the reasoning for the Directive on the promotion of the 
use of energy from renewable sources. Manufacturing and operation of RE have led to 157,000 jobs in Germany in 2004, and this number has grown to 280,000 in 2008. Spain has more than 1,000 enterprises in the RE industry, employing 89,000 workers directly and an estimated 99,000 indirectly. An EU modeling exercise found that, conservatively and under current policies, the RE industries would have about 950,000 direct and indirect full-time jobs by 2010 and 1.4 million by 2020 in the EU-15 [15].

In the developed and developing world, RE is seen as a means for increasing eco-development for tourism, and for driving economic revitalization. For example, the Austrian town of Güssing saw up to 400 tourists weekly by the late 2000s, coming to learn from the town's shift to RE [3]. A new hotel, heated and powered by RE, was built to accommodate the influx of tourists. The Navarre region in north-eastern Spain has witnessed creation of thousands of jobs and revitalization of many old villages since it began installing wind turbines in the early 1990s. Rizhao in China saw the number of tourists increase by 48 and 30 percent in 2004 and 2005, respectively, after enacting policies to increase use of $\mathrm{RE}$ and improve the local environment [16].

\subsection{Non-climate change environmental benefits}

The benefits of sustainable RE include improvements in air and water quality, and reduced impacts of fuel extraction, and energy production and use on biodiversity. For example, recognition of the risks to health, particularly to women and children, brought about by poor air quality indoors and out, has led governments to establish a range of initiatives, including policies to advance RE [3]. For example, avoiding negative environmental impacts is a major driver to promote clean energy technologies in China; the government of Pakistan intends to develop RE in order to avoid local environmental and health impacts of unsustainable and inefficient traditional biomass fuels and fossil fuel-powered electricity generation.

There is a growing recognition among scientists and policy makers that the exploitation of energy resources, if not properly controlled and managed, will have a harmful impacts on biodiversity of plant and animal species.

\section{Barriers to RE implementation}

IPCC-WGIII (2007) defines an RE barrier as "any obstacle to developing and deploying a RE potential that can be overcome or attenuated by a policy, program or measure". Barriers to RE deployment range from intrinsically natural properties of particular RE sources (for example intermittency and diffuse incidence of solar radiation) to artificial, unintentional or intentionally constructed, impediments (for example badly oriented, shadowed roof surfaces; a tilted (i.e. not having an equal playing field) power grid access conditions against independent generators).

IPCC-WGIII (2007) completes its barrier definition with: "Barrier removal includes correcting market failures directly or reducing the transactions costs in 
the public and private sectors by, for example, improving institutional capacity, reducing risk and uncertainty, facilitating market transactions, and enforcing regulatory policies." [5].

Barriers to RE deployment sets out what we have called an 'enabling environment' which is conducive to RE deployment through the removal of hurdles or barriers to development. In this context the following nine areas can be distinguished:

$\checkmark \quad$ There is no 'level playing field' for RE technologies, meaning that RE has to compete against other sources which have preferential treatment, whether in markets or network rules.

$\checkmark$ RE have to exist in regulations which maintain status, including avoiding stranded assets in existing infrastructure.

$\checkmark$ The incentives for Governments and private companies to support RE development are insufficient [1].

$\checkmark \quad$ Financing is either scarce or unreasonably costly for RE technologies.

$\checkmark$ Technology standards are lacking for (some) RE technologies and fuels [16].

$\checkmark \quad$ Import tariffs and technical barriers impede trade in renewables.

$\checkmark$ Permits for new RE plants are difficult to obtain.

$\checkmark \quad$ Energy markets are not prepared for RE [3].

$\checkmark$ RE skills and awareness is insufficient.

$\checkmark$ Financing barriers.

Policies address the failures and barriers which cause this gap between actual deployment and potential, while being subjected to their own failures.

\section{Financing barriers}

As we have seen, there are many barriers to RE deployment and policy and market failures to overcoming them. This paper focuses on their effect on the availability of financing. It looks first at the availability of capital; then moves on to financing for large scale projects; and lastly examines financing of small scale projects.

Private and public sources contribute to RE financing. When risks to investors are significant, public investment, or significant subsidies, or public-private partnerships (or other types of mixed financing / ownership) may be needed [2].

Most RE projects have, what is known as 'upfront' requirements (with an exception for biomass). This means that financing is relatively more important than for competing NSE projects. The availability of finance depends on general economic conditions, on the state of development of the capital markets in various countries, on the rating of the investor, on the type and characteristics of the RE project, etc. Even CDM envisioned for technology transfer does not address the point "until recently CER purchasers, even where those purchasers are financial institutions, have largely tended to limit their involvement in the project to being an off-taker of CERs, with payment to be made upon delivery, rather than providing project finance or becoming equity participant in the project" [8]. 
Developing nations with the largest potential for distributed, small-scale RE projects face the most and the highest financing hurdles due to "affordability for users and entrenched attitudes in some financial institutions. Affordability is a compound problem of low income, high upfront investment cost to obtain RE technologies, and no adequate financing mechanisms" [7]. In developing and undeveloped economies, RE deployment will grow if users are able to pay for their energy services. But there are not that many financial schemes and income generating activities that allow people to pay for investment and maintenance of RE options.

The "chequered history" of donor sponsored failing RE projects causes financial institutions to perceive a lack of reliability and long-term viability of RE technology [21]. This implies a strong call for robust quality control on all future RE investments especially in developing countries. However, donors providing capital continue to add strict preconceived conditions on the technology to be applied and how projects are to be managed, usually not matching the needs and priorities of recipient communities [19]. The latter often prefer local mechanical and thermal power supplies above expensive grid power. Access to funding by international institutions is difficult, even to GEF funds earmarked for RE. It continues that significant shares of the funds are spent on studies and reports, leaving too little money for actual equipment and installations on the ground and strengthening local capacity. "The transaction costs of developing smaller scale RE projects such as CDM projects (including the costs of external auditors, registration fees, consultants' fees and legal fees for the negotiation of CER purchase agreements and power purchase agreements) may be prohibitively high compared to the volume of CERs expected to be generated" [21]. Project appraisal studies often fail to incorporate important local aspects and values, also due to limited local stakeholder involvement [13].

In various countries, a stimulating RE policy contributed to easing of financing bottlenecks for large-scale RE projects (for example wind parks onshore and off-shore) [20]. Smaller-scale and independently owned distributed installations face more restrictive financing offers. Institutional creativity by cooperative ownership, micro-financing, energy service suppliers, and the like is still limited to niche experiments, and community-owned projects face several barriers [19].

\section{Concluding remarks}

A free market does not function according to rules of social responsibility and therefore needs to work within certain boundaries that serve social and environmental, as well as economic goals. Policy-makers have a social responsibility to set those boundaries. Legislators and regulators have it in their control to shift the future energy portfolio if they choose to decrease demand by improving energy efficiency and to push energy generation towards renewable energy. 
Financiers have a social responsibility to develop and deliver market solutions to the challenges of building a sustainable energy future. That energy future must take the form of a free energy market with less carbon, less fuel and fuel-price risk, and more and better access for the poor. Overall, policy is more important than resource potential in determining success, and policy design and implementation are critical to this success. Policies are most effective if targeted to reflect the state of the technology and available RE resources, and to respond to local political, economic, social and cultural needs and conditions. Moreover, policies that are clear, long-term, and robust, and that provide consistent signals generally result in high rates of innovation, policy compliance, and the evolution of efficient solutions.

Well-designed policies are more likely to emerge, and to lead to successful implementation, in an enabling environment. An enabling environment combines economic, technological, social and cultural, institutional and financial dimensions, including both the public and private sectors.

Coordination with policies related to other key and inter-linked sectors including agriculture, transportation, construction, technological development, and infrastructure - is also important.

Finally, achieving a sustainable energy system, one in which RE becomes the standard energy provider in a low-carbon energy economy, will require a structural shift to a more integrated energy service approach that takes advantage of synergies between RE and energy efficiency.

The financial community has different products and sectors to match the differing requirements of the stages in technology development. These products will be all the more successful within an environment of favorable social innovation and acceptance. The involvement of individuals and society in the transformation is crucial. This is the case in both developed and developing countries.

\section{References}

[1] Agnolucci, P. The effect of financial constraints, technological progress and long-term contracts on tradable green certificates. Energy Policy, 35(6), 3347-3359, 2007.

[2] Beck, F. and E. Martinot. Renewable Energy Barriers and Policies. In Encyclopedia of Energy: Ph-S. C. J. Cleveland (ed). Elsevier Academic Press, 2004.

[3] Flavin, C. and M. H. Aeck. Energy for development: the potential role of renewable energy in meeting the Millennium Development Goals. Bonn, Germany, Worldwatch Institute, Germany; Federal Ministry for the Environment, Nature Conservation and Nuclear Safety, Germany; German Agency for Technical Cooperation, 2005.

[4] Hvelplund, F. Renewable energy and the need for local energy markets. Energy, 31(13), 2293-2302, 2006.

[5] Intergovernmental Panel on Climate Change (IPCC). Climate Change 2007: Mitigation of Climate Change. IPCC Assessment Report 4. Cambridge, 
United Kingdom and New York, NY, USA, Cambridge University Press, 2007.

[6] International Energy Agency (IEA). Renewables for Heating and Cooling: Untapped Potential. Renewable Energy Technology Deployment. Paris, France, EA/OECD, 2007.

[7] International Energy Agency (IEA). Deploying Renewables: Principles for Effective Policies. Paris, France, IEA, 2008.

[8] International Energy Agency (IEA). World Energy Outlook 2009. Paris, IEA, 2009.

[9] Jacobson, M. Z. and M. A. Delucchi. A Plan to Power 100 Percent of the Planet with Renewables. Scientific American, November, 2007.

[10] Mendonça, M. and D. Jacobs. Feed-in Tariffs Go Global: Policy in Practice Renewable energy feed-in tariffs are growing in popularity as one of the most effective mechanisms of promoting renewable energy development. Renewable Energy World Magazine, September, 38-45, 2009.

[11] Pachauri, R. K. and A. Reisinger. Climate Change 2007: Synthesis Report. Contribution of Working Groups I, II and III to the Fourth Assessment Report of the Intergovernmental Panel on Climate Change. IPPC. Geneva, Switzerland, IPPC, 2007.

[12] REN21. Renewables 2005 Global Status Report: Notes and References Companion Document. Paris, France, Renewable Energy Policy Network for the 21st Century, 2005.

[13] REN21. Renewables 2007: Global Status Report. REN21 Secretariat and Worldwatch Institute. Paris, France and Washington, DC, USA, Renewable Energy Policy Network for the 21st Century, 2007.

[14] REN21. Renewable Global Status Report: 2009 Update. Paris, France, Renewable Energy Policy Network for the 21st Century, 2009.

[15] REN21. "Renewables Global Status Report: Energy Transformation Continues Despite Economic Slowdown." Retrieved October 29, 2009.

[16] Renewable Energy Technology Development (RETD). Barriers, Challenges and Opportunities. RETD. Paris, France, International Energy Agency, 2006.

[17] Sawin, J. L. Mainstreaming Renewable Energy in the 21st Century. Worldwatch Paper. T. Prugh. Washington, D.C., The Worldwatch Institute, 2004.

[18] Stern, N. The Economics of Climate Change: The Stern Review. Cabinet Office - HM Treasury. Cambridge, Cambridge, 2006.

[19] United Nations Environment Programme (UNEP). Financial Risk Management Instruments for Renewable Energy Projects: Summary documents. Paris, France, UNEP, 2004.

[20] United Nations Environment Programme (UNEP) and New Energy Finance Limited (NEF). Global Trends in Sustainable Energy Investment 2008: Analysis of Trends and Issues in the Financing of Renewable Energy and Energy Efficiency. I. a. E. Division of Technology. Paris, France, United Nations Environment Programme Sustainable Energy Finance Initiative and New Energy Finance Limited, 2008. 
[21] United Nations Environment Programme (UNEP) and New Energy Finance Limited (NEF). Global Trends in Sustainable Energy Investment 2009: Analysis of Trends and Issues in the Financing of Renewable Energy and Energy Efficiency. Division of Technology, Industry and Economics. Paris, France, United Nations Environment Programme Sustainable Energy Finance Initiative and New Energy Finance Limited, 2009. 